It is permissible to suggest, in view of these facts, that the clinical effects of benzedrine administration may be related to respiratory changes in the brain. It would be of interest to discover whether there accumulates in conditions of narcolepsy toxic bodies (? aldehydes) the formation of which is retarded by the administration of benzedrine

Details of the experimental results recorded above will be published shortly.

Biochemical Laboratory,

Cardiff City Mental Hospital. Oct. 26.

'Quastel and Wheatley, Biochem. J., 27, 1609 (1933).

2 P'ugh and Quastel, Biochem. J., 31, 256 (1937).

Pugh and Quastel, Biochem. J., 31, 2306 (1937). Blaschko, Richter and Schlossmann, Biochem.' J., 31, 2187 (1937).

- Pugh and Quastel (unpublished).

\section{Factors Determining Physical Size and Proportions}

THE mathematical methods ${ }^{1}$ devised to deal with the analysis and distribution of human ability and temperament ${ }^{2}$ can bo fruitfully applied to problems of isometric and allometric growth ${ }^{3}$ and to those of physical anthropology 4 .

A factorial analysis was undertaken of fourteen anthropornetric measurements obtained from two separate adult male samples, one consisting of 64 mental patients heterogeneous for age and disease, and the other of 50 university students homogeneous for age and social status. The two independent analyses gave strikingly similar results.

Without identifying statistical entities with bio. logical principles, it was shown that physique, in general, could be most usefully regarded as the re. sultant of two relatively independent factors or sets of processes, one determining the growth (or size) of the body as a whole in its various dimensions, and the other determining disproportionato development in length or circumference of the body. The establishment of racial or constitutional (growth) types would have to be based on a study of these two factors separately. These factors may ultimately be explicable in metabolic and genetic terms. The conventional indexes of somatometry would, if this view be correct, give little hope of revealing true racial or growth type differences, since 'type', as defined by excessive linear or circumferential development, is masked by the general processes governing size, and this latter factor would have to be statistically controlled if 'type' is to become ovident.

As regards the problem of physique and nutrition, the implication seems to be that two norms would be required : a norm for general or uniform development of the body, and another for typological variations.

Three measurements of the head, four of body length (arm, leg, trunk, stature), three of body breadth (shoulder, chest, pelvis), three of body circumference (chest, waist, pelvis) and one sagittal (chest depth) wero used. Coefficients of variation for the measurements descended in this order of magnitude : circumferential, sagittal, breadth, length, head. Of all the fourteen measurements, breadth and circumference of the pelvis and waist circumference were found most informative (that is, most discriminative) of general size or growth, and leg length together with circumference of waist and pelvis most informative of typological characteristics when the size infuences are statistically controlled.

Psychological Laboratory,

J. I. Cones. University College, London, W.C.I.

'Thomson, G. H., “The Factorial Analysis of Human Ability” (Univ. of London Press, 1939).

' Burt, C., Brit. J. Med. Prychol., 17, 158 (1938).

Huxler, J. S., and Teissier, G., C.R. Soc. Biol., 121 (1936).

- Clark, IV. E. Le Gros, Nature, 144, 804 (1939).

\section{Surface Features of Mars at the Recent Opposition}

Advantage has been taken of the recent very favourable opposition of Mars to make a close examination of the surface features. The 9 in. Cooke ploto-visual refractor has been employed, usually with a magnification of 250 . A fortnight of reasonably clear weather at the end of July assisted considerably, and nearly one hundred drawings of the disk have been made. The following is a summary of the chief points of interest revealed by these :

(1) Vast changes appear to have occurred on the north-east edge of IIare Cimmerium, where an apparently now dark marking has appeared. This seems to oceupy the region of Cyclops and Cerberus II, Pambotis Lacus having apparently become merged in it. It is separated from the main Mare Cimmerium by a narrow isthmus, broader at the north end and very prominent under certain illuminations. At the end of July it was very plain and obvious, being one of the darkest markings on the planet. The reduction of the numerous drawings of it has yet to bo madc, so that exact positions are not available at present.

(2) Until July 22, Heilas was bright and obvious with a sharply defined margin, particularly on the west, but on July 23 it has become dark and hazy with a much less definite outline. It remained so at every subsequent observation. At all times, even before July 23 , it was darker than the remainder.

(3) Edom Promontorium became very plain towards the end of August and was one of the most prominent features. Earlier, $a$ white region in Ausonia showed up very plainly.

(4) Iuventæ Fons showed as a dark point on July 10 but was not seen again, despite a close search for it.

(5) The North Pular region was a very interesting feature. Apparently it was covered by a very eccentrically situated cap of fog or ice. At times this was invisible but on other occasions it extended well on to the disk. Probably this can be accounted for by the rotation of the planet, although this point has not yet been investigated. Generally it was duller than the South Polar Cap, but on July 25 it was equal to it in brightness, while on August 4 it quite outshone everything on the disk, the South Polar Cap appearing very dull in comparison.

Various other features of interest have been noted, particularly in the Solis Lacus region, but, until the final reduction of the observations is complete, it is impossible to discuss them fully. It is hoped to publish the entire results in due course.
Carter Observatory,
Wellington, W.1,
M. Geddes.
I. L. Tronsen.

Now Zealand. Sept. 19. 